\title{
Pictures Worth a Thousand Words: A New Approach in Graduate School
}

\author{
Mary Ann Hollingsworth \\ University of West Alabama, Livingston, AL, USA
}

\begin{abstract}
Educators have shown increasing concern with capacity of students to engage in critical thinking and to exhibit correlation of constructs taught in to classroom to lessons applied to ongoing daily life. Graduate students in life span development were given two major assignments to study development over a person's life to that point in cognitive, cultural, emotional, moral, physical, and social development as well as application of major life developmental theories. One study was with a volunteer and was completed with traditional course paper format. The other study was on self - utilizing a Pecha Kucha format with inclusion on slides of personal photos and clip art that represented student development in these areas. Study results indicated increased efficacy of the presentation with integration of visual images over written reporting for to increase interest of students, to encourage exploration of symbols that uniquely represent the student's life as they add their meaning to the symbol, and to strengthen development of their own collaboration between eyes, left brain, and right brain. The study also indicated higher academic quality when integrating the arts modality than with the common challenges seen in written work such as depth and adherence to writing and APA style.
\end{abstract}

Keywords: arts in learning, critical thinking, student engagement

A common saying is that "A picture is worth a thousand words." Truly, a picture can evoke memories, emotions, feelings, and thoughts that might not be evoked by mere words alone in either written or oral format. The world of learning in the P12 environment has long integrated pictures as tools for learning. As students in higher education become more engaged in digital communication, value is indicated also for examination of pictures and other tools beyond the written and oral word to facilitate learning. Kyoko, Troncale, Trucks, Calhoun, \& Alvidrez, (2017) noted that student engagement was a core factor in classroom management that resulted in effective student learning. They discussed four technology tools that involved more pictures than words for enhancement of student engagement. Educreation (htpps://www.educreations.com) provides an integrative whiteboard and screencasting with which students could add pictures. Seesaw (https://web.seesaw.me/) provides a digital portfolio format in which students can upload pictures and other items besides the usual written word format to showcase their work.

Pecha Kucha presentation formats have become popular as a more useful and engaging format for presentation of information in the business environment. This format uses a Power Point presentation format in which there are 20 slides, with each slide shown for 20 seconds, thus providing quick and concise information to the audience. Levin and Peterson (2013) used this format with classes in an MBA program to promote

Mary Ann Hollingsworth, Doctor of Philosophy, Assistant Professor, University of West Alabama, Livingston, AL. 
student capacity to deliver presentations that are well-balanced, well-paced, and present strong evidence and argument for the points delivered. As this format requires the presenter to basically follow a script in narrative, it also promotes refinement of oral delivery skills.

\section{Background}

An examination of many graduate course requirements as seen in online learning platforms such as Blackboard reflect well only two of the eight types of intelligence activity from Howard Gardner's Frames of Mind. Sawyer (2010) noted that "Graduate study must of course include reading, research, and writing, as well as presentations and study group projects.” (p. 41). Students use Verbal Intelligence as they typically write papers, give verbal presentations, and possibly do group work that provides capacity for growth with Interpersonal Intelligence. Gardner's theory as described by Santrock (2017) includes additional types of intelligence such as Mathematical, Spatial, Bodily-kinesthetic, Musical, Intrapersonal, and naturalist. Santrock also describes the Triarchic Theory of Intelligence by Robert Sternberg which includes Analytical Intelligence, Creative Intelligence, and Practical Intelligence.

Right brain versus left brain learning has been the subject of attention at times among some educators. Right brain learning indicates a dominance of the right brain hemisphere over the left and left brain learning indicates a dominance of the left hemisphere. According to Saleh (2001), the right brain manages information in a more nonlinear manner and may focus on non-verbal input. The left brain then has prominence with more linear and verbal information. This focus has been embedded in attention to learning styles especially with students in P12 settings. Sometimes learning style has cultural relevance and a need exists to mold teaching to fit appropriate learning style. Young, Wright, and Laster (2005) examined learning style with African American students within research on effective instructional strategies to help close the gap on educational achievement for many of these students. Young, et al. specifically looked at right and left brain learning styles as framed by the model of Torrence, Reynolds, Riegel, and Ball as cited in Young, et al. (2005). This model use the terms Global for right brain learning and Analyitical for left brain learning. Global learning involved seeing, touching, and moving. Analytical learning involved processing both written and oral information. Young, et al. recommended that teachers use assessment of learning style to help mold their delivery of instruction.

Some research is available on application of these same principles with graduate students. Sawyer (2010) describes how she integrates assignments that tap into a variety of learning approaches to fulfill those expected tasks of graduate study. Examples that she gave were building models and artistic representation of course concepts. Saleh (2001) reported on hemispheric preference among various college majors. The majors that correlated with right brain dominance in learning style were arts, education, literature, law, and nursing. The majors that correlated with left brain dominance were business, engineering, and the sciences.

\section{Learning Enhancement}

Desirable outcomes of a learning process are for a student to want and seek knowledge as well as for a student to present evidence of mastery of knowledge from course content. Lapum and Hume (2015) discussed the efficacy of arts-informed teaching to strengthen student capacity for qualitative research. They specifically examined use of poetry, dance, film, and story. While they did not examine the integration of more visual art forms, they did note benefits that could apply equally as well. Lapum and Hume indicated that "arts have an inherent attribute that draws one in, invites query and curiosity, and prompts an audience/viewer to ask 
questions.” (p. 1227). These authors further discussed the benefit of arts-informed teaching in higher education as students grew in capacity for qualitative inquiry and capacity to correlate something that they may be familiar with to complex concepts in course content.

Brain function and learning. Much of the capacity for learning centers around the anatomy and functioning of the brain. Taylor and Lamoreaux (2008) discussed several pedagogical approaches that optimize brain and learning collaboration. One correlation was the process of memory which helps the learner to connect past experience with present experience or anticipated future experience. Course assignments that integrate representation of student past experience can strengthen application of the course constructs to the present or future. In similar fashion, Taylor and Lamoreaux described reflection as a process that uses connection with past experience to increase meaning to new experiences.

Garner and Holmes (2012) also examined correlation between neuroscience, education and art. This discussion integrated both the theory of collaboration between the right and left brain hemispheres as discussed earlier and Gardner's theory of multiple intelligences. Several examples were provided that exemplify the value of integration of work such as use of pictures or other art representations into study and student work. One example was with looking at exhibits in an art gallery. The art gallery director stated "When we're involved in looking at art the whole brain is fully engaged. It's one of the most sophisticated things we can do.” (p. 5). Another example was the collaboration between the brain and the types of problems a person encounters. Vision is then a collaboration of the eyes with the rest of the brain functions. Thus a picture or painting might promote a greater depth of collaboration than just the written word.

Critical thinking. Critical Thinking is an expressed need in today's world of education. Aliakbari and Sadeghdaghighi (2013) noted that promotion of critical thinking skills has been a prominent aim of educators since the 1960s. They also noted that there are many barriers that exist to impede development of student critical thinking skills. Per survey of 100 English teachers, these researchers found the top three perceived barriers to development of critical thinking skills were lack of motivation, concern of getting a good grade, and resistance to active learning. While these three were student generated, the authors noted various factors that influenced these such as lack of opportunity practice critical thinking skills and over-reliance on lecture as a prominent delivery modality of instruction.

The visual has been used to transmit constructs and ideas. Lazo and Smith (2014) examined the use of images to promote increase in critical thinking skills with students in a secondary school setting. A component of this research that is very relevant to the current study was inclusion of visual culture as "visual manifestations that belong to students' everyday lives to illustrate how there reading of these images interpret final meaning?” (p. 104).

\section{Project Description and Method}

Lifespan Development and Learning is a graduate level course that is required for most majors relating to education such as elementary education, school counseling, and physical education. Traditionally, this researcher has required students in this course to conduct a study of self as well as a study with a volunteer on multiple facets of lifespan development. Both of these include examination of areas of personal development cognitive, cultural, emotional, moral, physical, and social as well as application of two different theories of lifespan development as studied in the course. For several years, both of these studies were completed as written paper assignments. Upon learning about the Pecha Kucha format of presentation, this researcher then 
framed the study of self as a Pecha Kucha presentation with integration of visual images to convey the message of the student's development in the different areas. These visual images could be either photos or clip arts. In addition, the students were to provide a written script to accompany the slides and to verbally present the Pecha Kucha - in person for campus classes and via video recording for online classes. Based on the Pecha Kucha format of 20 slides with 20 seconds per slide, the directions for the script was to use 225-300 characters per slide with this including spaces as characters.

\section{Summary of Project}

234 students completed the two types of case studies, with the study on self as a Pecha Kucha format and the volunteer study as traditional formal paper format. Both studies included the same sections. The volunteer study required a formal APA style paper with title page, abstract, section headings, and reference list. The selfstudy included two slides per area of development and two slides per each theory application. The self-study also included a requirement to list references at the end of the written script, but not on a slide.

The use of the Pecha Kucha with integration of representative images was intended to promote integration of right and left brain learning as students reflected on past, present, and future development of self as well as exploration of visual images via photographs or clip art that presented connotations that most represented that facet of a student's development. In addition, there was a goal of increasing student enthusiasm for a major course assignment.

\section{Results}

Students evidenced more thorough commitment to the presentation of self via integration of images that represented their past and current lives as well as goals and plans for their future. This was seen in the interesting information shared about self, the diversity of photographs and clip art used, and in the tone of voice in both face to face and recorded presentations. Studies on self also presented much more adherence to assignment guidance and evidenced higher grade scores. Volunteer studies tended to exhibit results commonly seen in written papers, such as diversity of adherence to assignment instructions and rigors of writing and APA style usage. Content of volunteer studies tended to be objective and factual with very little sharing of interesting facts about the volunteers.

Surprisingly, the studies on self with integration of images often presented more detail in the narrative presentation than did the written studies on volunteers-even though instructions for the written studies requested details such as physical development facets of diet, exercise, illness, sleep, agility, and fine and gross motor movement. With the study on self, students sometimes shared such details, even though the instructions for this assignment were much more general.

Student comments on the two formats of study supported efficacy of integration of arts and opportunity to promote collaboration between both brain hemispheres. Students indicated that they enjoyed the development of their Pecha Kucha presentation, that it gave them opportunity to seek out pictures of family, school, etc. from the past that were meaningful to them. It gave them the opportunity to engage in some pleasant reminiscing and also gave them opportunity to dream for the future as they sought pictures or usually clip art that spoke to their goals. Perceptions of the volunteer written study were that it was a usual course paper to complete.

\section{Conclusion and Suggestions}

Academic rigor does indicate continuing use of written and oral verbal assignments that speak to student 
capacity to communicate knowledge in these modalities and to utilize requisite self-discipline with spelling, grammar, written organization and adherence to a designated style such as APA. The world of work still relies heavily on the use of the written and oral word in daily operation. Students would not be served well to fully discontinue written and oral verbal assignments.

Utilization of a different assignment format has provided promise to enhance student learning and application through integration of visual images that represent the intended construct and content. This different format promises opportunity to interest students more, to encourage exploration of symbols that uniquely represent the student's life as they add their meaning to the symbol, and to strengthen development of their own collaboration between eyes, left brain, and right brain. This format also provides students with a model of information presentation that they can be used in their post-degree work as educators or helping professionals.

This study focused on integration of pictures and clip art as visual representation of concepts and constructs. There are many more non-traditional modalities that could be integrated with promising results also. Pennisi (2012) discussed positive results of integration of the arts in understanding of social movements throughout history. Students visited cultural sites and examined arts expression of the times to note messages. Pennisi indicated that curriculum units had goals for students to "experience specific exemplary works of art as catalysts for imagination and to think critically about the class's learning objective” (p. 105). Students not only explored the items of art, but also engaged in production of a similar item. The final step in the process was to reflect on what the student had learned.

While this study focused on integration of visual art into study of human development over a life span, there are many courses in higher education that could benefit from similar integration of additional modalities of the arts such as music or drama. An example currently being conducted by the researcher is with the study of work with multicultural populations in which students are required to examine cultural life via modalities other than just a textbook description of a certain culture. In this course, students are required to examine fifteen different cultural frameworks through either film/television, art, music, literature, spiritual practice, or participation in an event that is core to the culture such as a festival celebration. Students have to diversify in this engagement with multiple modalities represented in their overall work on the project.

P12 educators have long integrated arts into their teaching in an effort to increase interest and engagement of their students. As students in higher education move away from traditional writing and reading to information processing via technology, the integration of arts into delivery of course constructs offers promise to renew student interest, to foster brain development for greater critical thinking, and to provide learning experiences that connect personal experience to lived experience of their world. This in turn can promote renewed interest in and preservation of the arts as preservation of the story of life.

\section{References}

Aliakbari, M. \& Sadeghdaghighi, A. (2013). Teacher's perception of the barriers to critical thinking. Procedia—Social and Behavioral Sciences, 70(1), 1-5.

Garner, R., \& Homes, D. (2012). The principles of neuro-arts education. The International Journal of the Humanities, 9(10), 1-9.

Karp, J. (2011). The power of words and pictures: Graphic novels in education: Using students' visual vocabulary as a learning tool. American Libraries, 42(7/8), 33-35.

Kyoko, J., Troncale, J., Trucks, C., Calhoun, C. \& Alvidrez, M. (2017). Cool tools for school: Twenty-first century tools for student engagement. Delta Kappa Gamma Bulletin, 84(1), 53-58.

Lapum, J., \& Hume, S. (2015). Teaching qualitative research: Fostering student curiosity through an arts-informed pedagogy. The Qualitative Report, 20(8), 1221-1233. 
Lazo, V. G., \& Smith, J. (2014). Developing thinking skills through the visual: An a/r/topographical journey. International Journal of Education Through Art, 10(1), 99-116.

Levin, M. A., \& Peterson, L. T. (2013). Use of Pecha Kucha in marketing students' presentations. Marketing Education Review, 23(1), 59-64.

Pennisi, A. C. (2012). A partnership acaross boundaries' Arts integration in high schools. Teaching Artist Journal, 10(2), 102-109.

Saleh, A. (2001). Brain hemisphericity and academic majors: A correlation study. College Student Journal, 35(2), 193-200.

Santrock, J. (2017). Life-span development. (16th ed.). Boston: McGraw-Hill Publishers.

Sawyer, C. H. (2010). Beyond the lecture: Innovative learning approaches to connect with 21st century graduate students. Global Partnership Management Journal, 1(1/2), 37-44.

Taylor, K., \& Lamoreaux, A. ( 2008). Teaching with the brain in mind. New Directions for Adult and Continuing Education, 119, 49-59.

Torrance, C., Reynolds, R., Riegel, I., \& Ball, O. (1977). Your style of learning and thinking. Gifted Quarterly. 2, 563-573.

Young, C. Y., Wright, J. V., \& Laster , J. (2005). Instructing African American students. Education, 125(3), 516-524. 